E International

Passenger Transport in Rural and Sparsely Populated Areas in France

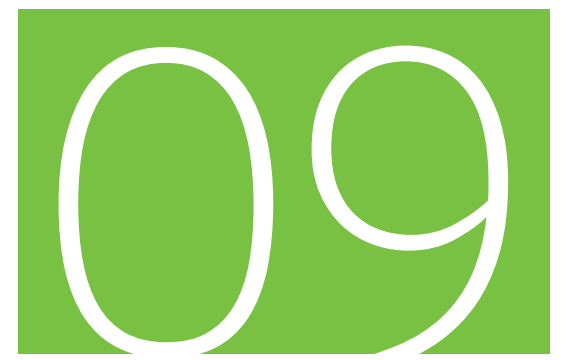

Discussion Paper 2015•09

Christophe Saroli

Cerema, Lyon, France 


\section{Passenger transport in rural and sparsely populated areas in France}

Discussion Paper No. 2015-09

Christophe SAROLI

Cerema, Lyon, France

March 2015 


\section{THE INTERNATIONAL TRANSPORT FORUM}

The International Transport Forum at the OECD is an intergovernmental organisation with 54 member countries. It acts as a strategic think-tank, with the objective of helping shape the transport policy agenda on a global level and ensuring that it contributes to economic growth, environmental protection, social inclusion and the preservation of human life and well-being. The International Transport Forum organises an Annual Summit of ministers along with leading representatives from industry, civil society and academia.

The International Transport Forum was created under a Declaration issued by the Council of Ministers of the ECMT (European Conference of Ministers of Transport) at its Ministerial Session in May 2006 under the legal authority of the Protocol of the ECMT, signed in Brussels on 17 October 1953, and legal instruments of the OECD.

The Members of the Forum are: Albania, Armenia, Australia, Austria, Azerbaijan, Belarus, Belgium, Bosnia and Herzegovina, Bulgaria, Canada, Chile, China (People's Republic of), Croatia, Czech Republic, Denmark, Estonia, Finland, France, Former Yugoslav Republic of Macedonia, Georgia, Germany, Greece, Hungary, Iceland, India, Ireland, Italy, Japan, Korea, Latvia, Liechtenstein, Lithuania, Luxembourg, Malta, Mexico, Republic of Moldova, Montenegro, Netherlands, New Zealand, Norway, Poland, Portugal, Romania, Russian Federation, Serbia, Slovak Republic, Slovenia, Spain, Sweden, Switzerland, Turkey, Ukraine, United Kingdom and United States.

The International Transport Forum's Research Centre gathers statistics and conducts co-operative research programmes addressing all modes of transport. Its findings are widely disseminated and support policymaking in member countries as well as contributing to the Annual Summit.

\section{Discussion Papers}

The International Transport Forum's Discussion Paper Series makes economic research, commissioned or carried out at its Research Centre, available to researchers and practitioners. The aim is to contribute to the understanding of the transport sector and to provide inputs to transport policy design.

ITF Discussion Papers should not be reported as representing the official views of the ITF or of its member countries. The opinions expressed and arguments employed are those of the authors.

Discussion Papers describe preliminary results or research in progress by the author(s) and are published to stimulate discussion on a broad range of issues on which the ITF works. Comments on Discussion Papers are welcomed, and may be sent to: International Transport Forum/OECD, 2 rue André-Pascal, 75775 Paris Cedex 16, France.

For further information on the Discussion Papers and other JTRC activities, please email: itf.contact@oecd.org

The Discussion Papers can be downloaded from: www.internationaltransportforum.org/jtrc/DiscussionPapers/jtrcpapers.html

The International Transport Forum's website is at: www.internationaltransportforum.org

This document and any map included herein are without prejudice to the status of or sovereignty over any territory, to the delimitation of international frontiers and boundaries and to the name of any territory, city or area. 


\section{Table of contents}

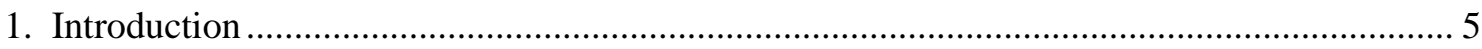

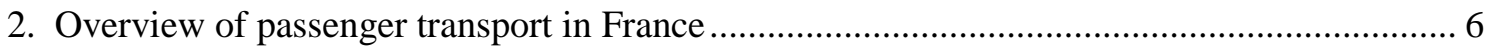

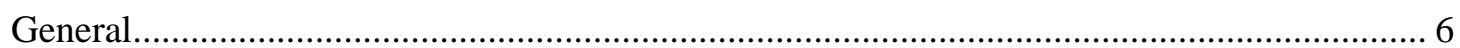

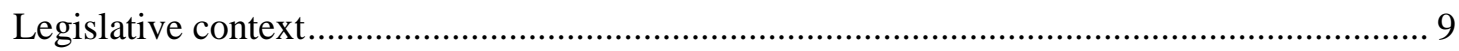

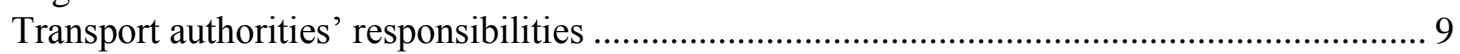

Public transport financing outside Paris .......................................................................... 11

3. Mobility planning: sustainable urban mobility plans …........................................................... 14

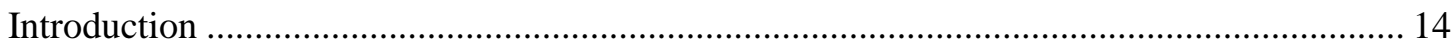

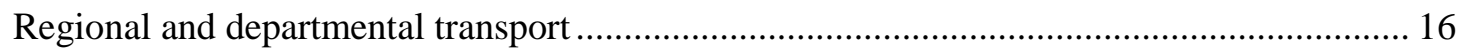

4. Demand-responsive transport:_a high level of flexibility for transport services .................... 18

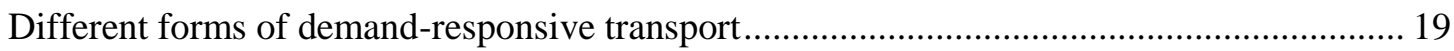

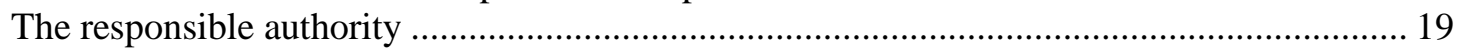

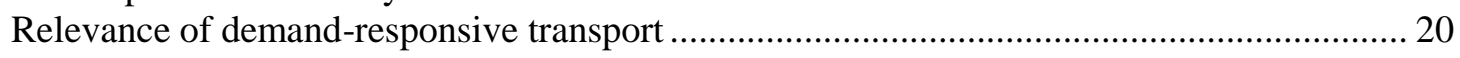

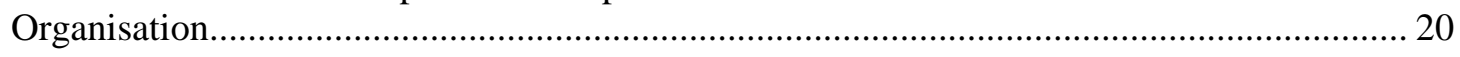

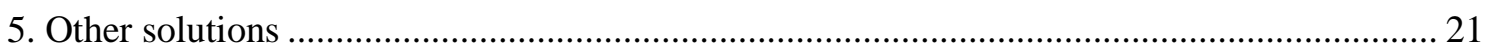

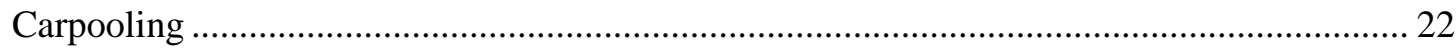

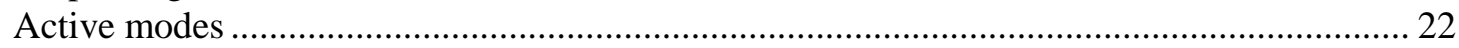

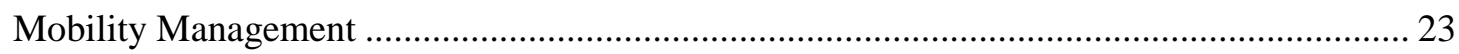

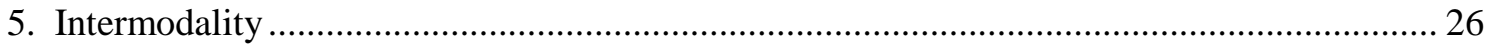

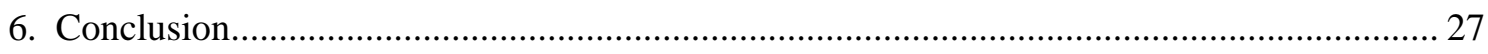

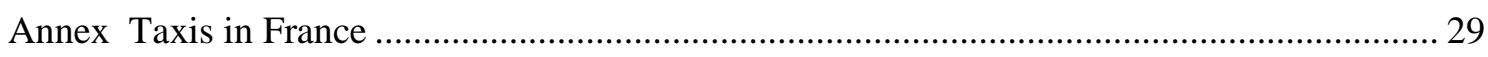

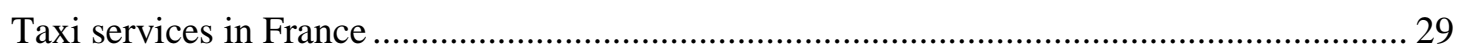

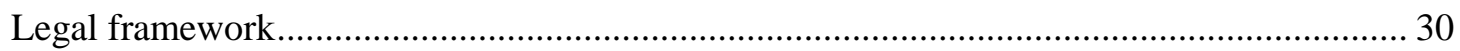

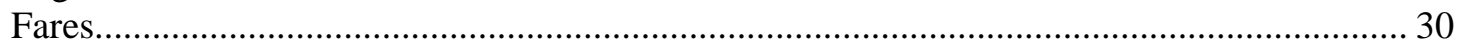

Private hire vehicles and chauffeur-driven passenger vehicles ............................................. 31 



\section{Introduction}

Improving mobility is a major issue in sparsely populated areas. The low population density in these localities often means that longer journeys are required to access services, carry out everyday activities or maintain social links. Whole sections of the population - in particular older people, young people, stay-at-home parents in single-car households, and seasonal workers - are effectively handicapped in mobility terms by inadequate public transport provision and an overdependence on people who have cars.

The right to transport is enshrined in French legislation, in particular the law known as "LOTI" (domestic transport orientation law - Framework law on inland transport), passed in 1982:

"The progressive implementation of the right to transport allows users to travel in reasonable conditions in terms of access, quality and price, as well as in terms of the cost to public authorities, in particular by using a mode of public transport".

However, the application of this law is a delicate matter in sparsely populated areas, as conventional public transport services, highly dependent on high-volume transit, are not always suitable for a widely dispersed population.

Furthermore, it is becoming more and more difficult for these services to meet increasingly complex and individualised mobility needs. Nevertheless, there is a real demand for mobility in these areas (whether for leisure, shopping or work), together with growing concerns regarding sustainable development.

In the context of increasing private car use, rural areas, like medium-sized towns, are in a position where they need to find alternative transport solutions to address changing mobility issues. A broader range of approaches must be taken to find innovative transportation solutions for the local population, given the fact that such towns have to deal with increasingly diverse transportation needs, in terms of both time and space.

One solution is to make public transport services more attractive in terms of transport supply and quality of service. The density of population is a key factor, since it usually prohibits the development of "heavy" public transport systems (e.g. metro or tram network).

Indeed, faced with the challenges of sustainable development, noticeable changes are being made to transport policies. The objective is no longer to adapt supply to ever-fluctuating demand, but to try to concentrate and direct this demand towards economical, efficient and environmentally friendly forms of mobility.

From this point of view, different actions are developed in France. The range of actions includes planning tools, mobility management and different transport solutions.

Global transport planning tools, sustainable urban mobility plans (plans de déplacements urbains PDU), were introduced in the LOTI in 1982 in order to tackle mobility challenges. While these plans were first introduced in urban areas, they are increasingly implemented in large and rural areas. 
Mobility Management (MM) is another concept developed to promote sustainable transport and manage the demand for car use by changing travellers' attitudes and behaviour. At the core of Mobility Management are "soft" measures like information and communication, organising services and coordinating the activities of different partners. "Soft" measures most often enhance the effectiveness of "hard" measures within urban transport (e.g. new tram lines, new roads and new bike lanes). Mobility management measures (in comparison to "hard" measures) do not necessarily require large financial investments and may have a high benefit-cost ratio.

Low density areas and medium-sized towns are at the ideal scale for developing flexible public transport solutions, whereby services can be more or less adapted to the user's needs, such as demandresponsive transport (DRT) or carpooling.

Demand-responsive transport (DRT) can provide a solution that is particularly suited to sparsely populated areas, thanks to its flexibility, its ability to adapt to local contexts, and the fact that costs can, to some extent, be controlled. It satisfies people's right to transport, within reasonable financial limits for the community, and it can be adapted to suit all categories of users - the elderly, teenagers, working people, pensioners and people with reduced mobility, etc.

Carpooling represents a credible and attractive mobility solution, in addition to public transport and other mobility services, to reduce the individual use of private cars, particularly in sparsely populated areas, where public transport can hardly be implemented at reasonable cost, and where carpooling can be an effective solution. Carpooling has become increasingly visible in recent years. Its development could help to solve many mobility issues in the current economic crisis, both for users and public bodies. Carpooling obviously has significant growth potential. Many local carpooling schemes and public initiatives to support the practice have been implemented in France. But there are still efforts to be made to promote this practice.

\section{Overview of passenger transport in France}

\section{General}

The last decade saw significant changes in mobility behaviour in France. Individual mobility - i.e. the number of daily trips made by each individual - which had risen significantly until the mid-2000s, remained stable and in some cases even fell, from 2005 onwards. At the same time, car use fell for the first time in large conurbations. At national level, motor vehicle traffic levels have stabilised. Public transport, boosted by the revival of the tram, has seen passenger numbers increase, particularly in those conurbations with highly effective public transport systems. Cycling, meanwhile, has increased. These new and mainly urban trends are expected to spread across sparsely populated areas in the coming years. Cars will play a different role in the coming decade.

Individuals have been increasingly affected by higher transport costs. It is generally accepted that this fragility is being felt increasingly at local level, with a growing impact on mobility, thereby reinforcing socio-spatial inequalities.

One can see a growing awareness of climate change due to human activity - and transport in particular - and the finite nature of oil resources. This growth in public awareness has not, however, 
led to genuine collective mobilisation as it remains mitigated by other concerns such as purchasing power and lifestyles.

Public initiatives have changed in response to the growing social demand for greater consideration of individual needs, while mobility behaviour has continued its trends towards greater diversity. The decentralisation process which began in the 1980s continues, giving local authorities even greater freedom to set their own transport policies. One of the key features of the last decade has been a trend for local authorities to adapt central government policies to suit their own contexts. The Grenelle de l'Environnement (the French government's environmental round table) at the end of the 2000s, however, marked the return of national (and even international) climate change-related issues to centre stage.

Individual mobility is no longer rising. Behaviour is changing; the general trend shows that individual mobility has stabilised in France, supported by transport policies introduced since the LOTI law (French framework law on domestic transport) of 30 December 1982. This law forms the basis of land-based public transport organisation in France.

The French law on air quality and the rational use of energy (LAURE), introduced in 1996, made urban transport plans (PDUs) mandatory for conurbations with a population greater than 100,000 . These PDUs require local authorities to take a holistic approach to transport management, with the aim of reducing vehicle traffic.

As a result, local authorities introduced new transport projects, made substantial investment in public transport and redeveloped city centres, introducing road-sharing schemes that favour public transport and environmentally friendly modes of transport.

Although it is difficult to identify specific factors that have had the greatest influence, it is clear that the most significant changes have occurred in those places where deliberately long-term transport policies have been introduced.

These changes cannot, however, be attributed to public initiatives alone. The economic crisis at the end of the decade had a marked influence on mobility, and on car use in particular, along with a general trend towards greater concern for environmental issues.

Local politicians therefore tackled transport issues head on, placing public transport at the top of the policy agenda. The result was the first generation of PDUs, which appeared in the 2000s, focusing primarily on public transport systems using dedicated lanes. Policies in this area have remained somewhat limited due to specific local situations, with less densely populated cities and smaller conurbations not experiencing the same level of growth in public transport use.

Walking and cycling, which were once seen as old-fashioned and overlooked by transport policymakers, are now viewed as modes of transport in their own right. Legislators have taken steps to encourage use of these modes of transport, providing local authorities and developers with new tools such as pedestrian priority zones and shared $30 \mathrm{kmph}$ zones. Public space planning initiatives have favoured these active modes of transport as part of efforts to improve the living environment for local residents and to limit excessive car use.

The use of active modes of transport remained generally stable in the last decade, although it increased in the centres of large conurbations, probably in connection with self-service bicycle schemes which have been introduced on a large scale since the mid-2000s, and which have greatly enhanced the profile of the bicycle. Despite this, there remains substantial room for manoeuvre in terms of short-distance trips, particularly in suburban areas and smaller cities. This is also a public health issue, as their regular use helps to reduce the risk of cardio-vascular diseases and obesity. 
Car use in cities is on the decline for the first time. Furthermore, there appears to be a growing disconnect between car ownership and car use. While ownership is on the rise, people are using their cars less often. The emergence of a more rational relationship with the car is likely, in future, to lead to growth in car-sharing. One of the key challenges in the coming years will be to encourage a gradual shift from the car as a "possession" to the car as a "service".

Outside the centres of large conurbations, car use remains stable at best (in smaller city centres) or continues to rise. Cars account for $80 \%$ to $85 \%$ of all trips in periurban fringes. At the same time, the use of public transport and active modes of transport is on the decline, including in the fringes of large conurbations.

These changes demand innovative solutions to improve transport service in these areas. The 2000s saw the development of public transport systems such as Bus with a High Level of Service (BHLS) and Demand-Responsive Transport (DRT), which is a less costly alternative for smaller cities and less densely populated areas.

There has been a substantial increase in the number of trips made in periurban fringe areas (up 44\% between 1994 and 2008), primarily due to their increasing demographic size. Despite receiving less attention than periurban areas, suburbs account for more than a quarter of all trips made each day in France, with the total number increasing by $9 \%$ between 1994 and 2008. The increase in the number of trips between different types of area also poses a challenge: encouraging the movement of jobs away from urban centres and towards the suburbs while ensuring that these urban centres remain able to attract residents from the periurban fringes.

The residents of urban centres tend to make shorter trips and use modes of transport other than the car. They therefore emit less $\mathrm{CO} 2$ per capita than their suburban counterparts as a result of their daily travel. These low emissions for local trips more than make up for the higher emissions they produce when making long-distance trips.

While periurban residents emit most $\mathrm{CO} 2$ per capita, it is the residents of the suburbs that produce most $\mathrm{CO} 2$ as a whole, due to their sheer number. It is here - especially in large conurbations - that the battle against greenhouse gas emissions must therefore be fought.

The change in mobility practices reflects a change in lifestyles, with people spending less time at work and more time visiting family and friends, spending more time at the computer, etc. Households' daily routines and travel practices are governed by the activities of their members.

In order to better understand the challenges that this poses, local authorities have created new "time offices" (Bureaux des Temps). The purpose of these new structures is to place citizens at the heart of transport policies.

However, they remain isolated for the time being. Despite the fact that people are now spending less time at work, the challenges that this activity poses remain significant. Work-related trips account for $20 \%$ to $25 \%$ of all trips. They also tend to be longer than other trips, are usually made by car and are concentrated during rush hour. These types of trip therefore remain a key priority in transport service policy.

Elderly people are travelling more than before, making more trips by car and walking less. Furthermore, the size of the elderly population is rising. As well as the environmental impacts of these changes, it is important to consider the specific mobility needs of this population and to ensure that they continue to have access to local shops and services. This will enable elderly people to continue living at home and encourage walking - particularly important from a health perspective.

This issue raises the more general question of travel for people with reduced mobility. It is important to remember, in this respect, that the French "Handicap" law of 2005 requires that public transport networks be made accessible to people with reduced mobility by 2015 . 
Experts agree that rising fuel prices are linked to economic fluctuations that are gathering pace and are difficult to predict. In this situation, access to urban functions, and to jobs in particular, can become increasingly difficult. Periurban areas, where residents are highly dependent on cars, are particularly severely affected by this phenomenon. It affects not only poor households, but also the middle classes who have moved out to the suburban fringes to benefit from cheaper housing. These groups are now especially vulnerable to fuel price rises.

\section{Legislative context}

Transport authorities are public bodies with responsibility for organising public transport services and setting transport policy in the area that they cover.

The concept of transport authority, and the roles and rights of these bodies, are set out in the socalled "LOTI" law (French framework law on domestic transport) of 30 December 1982. This law forms the basis of land-based public transport organisation in France.

Since this law was introduced, a series of additional legislative texts have come into force, further strengthening the role of urban transport authorities:

- French law of 30 December 1996 on air quality and the use of energy (LAURE);

- French law of 13 December 2000 on solidarity and urban renewal (SRU). This law strengthened powers in the field of transport policy, making such policies more prescriptive in terms of road-sharing and parking, and requiring consistency between transport policy and urban planning; and

- French law of 11 February 2005 on equal rights and opportunities, involvement and citizenship of people with disabilities, which sets out the requirements incumbent on urban transport authorities in terms of accessibility.

More recent laws affecting transport organisation include the French laws of 3 August 2009 on the Grenelle de l'Environnement (the French government's environmental round table) implementation schedule and the French law of 12 July 2010 formalising a "national commitment to the environment".

Finally, the French law of 16 December 2010 on the reform of local government - although not specifically about transport - should have a substantial impact on the number and type of transport authorities in existence, broadening their remits and, eventually, strengthening the powers of some of these authorities.

The three laws outlined above are designed to improve transport governance, by strengthening cooperation arrangements or introducing new institutional tools and systems. There are also provisions that improve coordination between urban transport authorities and other authorities and bodies (roads, urban planning, parking, etc.).

It is important to note that, as of 1 December 2010, all laws covering transport organisation were unified under a single Transport Code.

\section{Transport authorities' responsibilities}

Urban transport authorities (296 as of 1 January 2011) may exist in a variety of legal forms. In most cases, they are intercommunal authorities. 
Urban transport authorities are closely linked with a clearly defined urban transport area (PTU). Local authorities have the power to create an urban transport area at their own initiative. The local government representative (prefect) submits the proposal to the departmental authority (Conseil Général), then formally approves the creation of the urban transport area. Whenever an urban transport area is created, a new urban area authority is automatically created. Similarly, whenever the boundary of one of these structures is extended, the associated urban transport area is automatically extended.

Under French law, urban transport authorities are "authorities with the power to organise general urban public transport services. They also have the power to organise demand-responsive transport services."

In this sense, urban transport authorities are not responsible for road transport outside their urban transport area or rail transport on the national rail network.

The division of powers between the different echelons of local government (regions, departments, municipalities, and groups of municipalities) is specified under the LOTI law.

In terms of organisation, the responsibilities of urban transport authorities are as follows:

- Selecting the form of management (direct or through delegation) and drawing up contracts with operators;

- Determining coverage objectives;

- Setting a fares policy designed to promote "the most effective use of the transport system, in both financial and social terms" and which does not exclude the poorest members of the local population from transport services;

- contributing to transport service financing. In order to achieve this aim, urban transport authorities may decide to introduce a transport tax (versement transport-VT). This is a tax on both public- and private-sector employers, with the amount collected going directly to urban transport; the level of this tax is limited by law; and

- Creating transport system infrastructures.

Urban transport authorities are also responsible for drawing up an "accessibility master plan" to ensure that people with disabilities and people with reduced mobility can access transport services (pursuant to the French law of 11 February 2005).

The urban mobility authority prepares the urban mobility plan. Central government departments and regional and departmental councils (like transport authorities and road network managers) are involved in the preparation process.

As of 1 January 2011, there were 296 urban transport authorities in France, with a variety of legal forms. The simplest type of urban transport authority is the municipality (commune). In practice, however, this structure is only used to set up transport networks in small urban areas.

Beyond a certain population size, municipalities tend to join forces under a single, intercommunal structure which also acts as the transport authority.

This type of intercommunal structure normally fulfils other functions in addition to urban transport organisation (urban policy, economic development, spatial development, etc.)

In some rare cases, the urban transport authority may also be a joint management board (syndicat mixte), comprising different types of local authority (municipality, intercommunal co-operation authority, department). 
In 2011, the breakdown of urban transport authorities was as follows:

- $26 \%$ were municipalities;

- $58 \%$ were communities (groups of municipalities with their own tax levying powers and with responsibilities covering multiple sectors). This figure includes intercommunal authorities, urban area authorities (the most common type of urban transport authority, accounting for $41 \%$ of the total), and greater urban authorities;

- $6 \%$ were intercommunal syndicates with sole responsibility for urban transport; and

- The remaining $10 \%$ were joint management boards comprising different types of local authority.

\section{Public transport financing outside Paris}

The LOTI law states that urban public transport may be funded by a number of different parties: "users, public local authorities where applicable and (...) other public and private beneficiaries who, while not users of the service, gain a direct or indirect advantage from the service".

Urban public transport users fund the service through the purchase of transport tickets. The French urban public transport system is also funded by a specific Transport Tax. This tax is levied on employers with more than nine employees working within a given public transport area. The transport authority has the power to introduce this tax. The revenue collected from the tax can be used to fund both investment expenditure and network operating expenditure.

Both local authorities and central government contribute to urban public transport network development expenditure. Local authorities provide the majority of the investment funding, with central government making a smaller contribution. Operating expenses are covered entirely by the local authority, however.

In 2010, urban transport networks (operation and investment) outside the Paris region were funded as follows:

- employers, via the Transport Tax (44\%);

- local authorities, via their own taxation (28\%) and loans (8\%);

- passengers, via fare revenues $(16 \%)$;

- central government (1\%);

- other sources $(3 \%)$.

Therefore, outside Paris, urban transport authorities play a key role in funding their networks, setting the Transport Tax rate and deciding on passenger fare levels and rises which, in turn, affect fare revenues. They also often guarantee the financial balance of the urban public transport services by making their own contributions. The level of urban transport authority participation in transport funding has risen sharply in recent decades.

\section{Passenger financing in networks outside Paris}

The fares policy reflects the urban transport authority's political, social, technical and financial aspirations. It must comply with the general principles that govern public service delivery and public accounting: equal access to transport, equal treatment of public service users and budgetary balance. 
The urban transport authority therefore decides the transport tickets that will be available on its public transport network and sets the price at which these are sold to users. This enables the authority to calculate its fare revenue which, in turn, will be used to fund public transport operation.

The operator may offer technical expertise in terms of fares and ticketing and submit proposals to the urban transport authority. However, the urban transport authority has the final say on the fares policy that will be implemented within its network (e.g. fares reductions for people whose income is below a certain threshold, or the introduction of multimodal pricing arrangements).

The urban transport authority compensates the operator for the loss of revenue caused by these reduced or zero-rate fares.

Fare revenues collected from the sale of transport passes to users only cover part of total urban transport network operating expenditure.

In 2010, fare revenues amounted to $€ 1,028$ million, while network operating expenditure stood at $€ 4,926$ million, meaning that fare revenues covered $21 \%$ of total urban network operating costs. There are significant local differences: the more highly developed the network, the greater the difference between fare revenues and operating expenditure.

In 2010, total expenditure (including all operating and investment costs) on urban transport networks outside Paris stood at $€ 6,516$ million. Fare revenues therefore accounted for a little over $16 \%$ of total annual expenditure.

This situation is the result of a deliberate decision by local authorities to encourage public transport use. In 2010, observations showed that networks outside the Paris region:

- Had competitive fares: the average ticket price per unit was $€ 1.13$, with a book of 10 tickets costing an average of $€ 8.70$ and a monthly subscription $€ 27.66$;

- Offered an attractive range of fare options, with significant savings for subscriptions and discounts for certain types of user (young people, the elderly, etc.), as well as special social fare rates for other types of user (unemployed, people with reduced mobility, etc.) in line with the "right of transport" principle and pursuant to legal obligations.

\section{Employer financing}

\section{The Transport Tax}

A public transport financing system, known as the Transport Tax, was introduced in the Île-deFrance (Paris) region in 1971, and in France's other cities in 1973. This is a special tax levied on public and private employees with more than nine employees in an urban transport area with a population of more than 10,000 , or lower if the urban transport area includes at least one "tourist commune". The revenue from this tax is allocated to urban public transport. It is used to fund operating and investment expenditure, as well as projects to improve intermodal travel actions between bicycles and public transport.

The Transport Tax is optional outside the Paris region. The decision to levy this tax, and the rate at which it is set, is taken by the urban transport authority, within the legally defined limits. In 2010, the Transport Tax had been introduced by 226 urban transport authorities outside the Paris region. These included:

- 20 metropolitan areas with dedicated-lane transport systems, which received $56 \%$ of total Transport Tax revenues;

- 57 metropolitan areas with more than 100,000 inhabitants, which received $34 \%$ of total Transport Tax revenues; 
- 149 metropolitan areas with fewer than 100,000 inhabitants, which received $9 \%$ of total Transport Tax revenues.

Transport Tax revenues have increased by almost $51 \%$ in 10 years, for the following three reasons:

- some existing urban transport areas have expanded and new ones have been created, increasing the number of employers liable to pay the tax;

- the corresponding wage bill has increased due to economic growth;

- rates have increased (due or not to dedicated-lane transport systems).

Throughout this period, the percentage of total urban public transport financing (excluding loans) coming from the Transport Tax remained at between $43 \%$ and $48 \%$.

\section{Transport reimbursement (Prime transport)}

A law created aid measures for employees, financed by the employer with State assistance, to fund their travel expenses between their usual place of residence and their workplace.

This system is twofold:

- the mandatory payment by the employer of half of the subscription to a public transport service or rental of bicycles purchased by its employees for their home-work commute;

- the transport reimbursement (prime transport) that is optional for the employer and covers all or part of the costs to use a personal vehicle incurred by its employees for their home-work commute. This payment benefits from a social charge and tax exemption in favour of both the employer and employee up to a limit of $€ 200$ per year. This optional payment is in addition to the mandatory payment of subscription costs for public transport or the rental of bicycles.

\section{Public funding}

\section{Local authority contribution}

In 2010, local authorities contributed $28 \%$ of total urban transport network funding (investment and operation) directly from their own budgets. When the Transport Tax and loans are included, this figure rises to $80 \%$.

Outside the Paris region, the portion of network operating costs not covered by traffic revenues, Transport Tax revenues or operating subsidies from partner local authorities is funded directly by the urban transport authority, within the limits of the contractual agreement between the authority and its operator.

Investment financing, on the other hand, comes from several different sources:

- Urban transport authorities (own budget + Transport Tax + loans);

- Central government (via infrastructure subsidies); and

- Other partners (local authorities, Europe).

Outside the Paris region, investment expenditure amounted to $€ 1.59$ billion in 2010 , with $91 \%$ of this investment occurring in urban transport authorities with more than 200,000 inhabitants, with or without dedicated-lane transport systems.

\section{Central government contribution}

The Grenelle de l'Environnement (the French government's environmental round table) reignited interest in developing dedicated-lane public transport networks. This renewed interest was based not 
only on the fact that such systems would help to reduce greenhouse gases by limiting private car use, but also on their ability to mitigate urban congestion and provide high-quality transport options to a large number of people.

In order to meet its target, the French government decided to contribute to the funding of urban public transport projects introduced by urban transport authorities by providing dedicated-lane transport system investment subsidies under a national urban transport "call for projects". The government also provides public funding for multi-year joint government/region project contracts (contrats de projets État-Région-CPER). A total of $€ 103$ million was allocated to this scheme for the 2007-2013 period.

\section{Mobility planning: sustainable urban mobility plans}

\section{Introduction}

Global transport planning tools, the sustainable urban mobility plans (plans de déplacements urbains - PDU), were introduced under the LOTI in 1982 in order to tackle mobility challenges.

Sustainable urban mobility plans started out as global transport planning tools in urban areas for the development of public transport and active modes (walking and cycling) in the 1980s and 1990s, and have gradually taken on more importance around more recent issues or issues that received insufficient attention in the early decades: environment and climate change, accessibility for people with reduced mobility, transport and urban planning, parking management and the transportation of goods.

Thirty years after their creation, PDUs have demonstrated their effectiveness in influencing inhabitants' mobility: decreased car use in major urban centres, increased use of public transport and development of active modes. Their success has encouraged many medium-sized towns to engage in voluntary approaches and the PDU is now one of the "sustainable urban mobility plan" models promoted by Europe in its Action Plan on Urban Mobility.

However, implementation problems remain, particularly due to the complexity of integrating the PDU into the hierarchy of planning documents, the multiplicity of stakeholders involved in governance and the need for cooperation between transport authorities beyond the scope of application of the PDU.

So the PDU today faces many challenges which it must take up if it is to strengthen its contribution to the integration of urban and transport policies.

After forty or so PDUs in the 1980s, they became compulsory in 1996 for urban areas of more than 100,000 inhabitants. The first wave of compulsory PDUs was approved in the early 2000s. Most of these first PDUs were revised or are being revised in the early 2010s. Since 2005, PDUs have gradually conquered medium-sized towns, a movement that has picked up speed in recent years. Today, nearly 80 PDUs are being implemented, and about as many simplified procedures in towns of less than 100,000 inhabitants.

The PDU is a comprehensive transport planning tool that determines the principles governing the organisation of passenger and freight transport, traffic and parking within the scope of urban transport. The development process is led by the French urban transport authority (autorité organisatrice des 
transports urbains - AOTU) and involves many institutional stakeholders, both from civil society and economic ones. Its content has changed several times and its objectives have gradually turned towards the promotion of sustainable mobility in relation to urban policy.

Then the SRU law, in 2000, aimed to strengthen social and urban cohesion. It introduced regional integrated development plans (Schéma de cohérence territorial - SCoT) and local urban development plans (Plan local d'urbanisme - PLU) and placed the PDU within this hierarchy of planning documents.

Since the SRU law, mobility policies have been better integrated into urban planning, and the 2010 Grenelle II law 2010 now gives "reduce the need to travel" as one of the objectives of urban plans (SCoT and PLU).

Several recent PDUs have been drawn up to link transport and urban planning better, like the 2011 Nantes PDU whose first topic is to build a town in which trips are short, or that of Montpellier in 2012 which clearly shows its consistency with the SCoT.

Since the SRU law, mobility policies have been better integrated into urban planning, and the 2010 Grenelle II law 2010 now gives "reduce the need to travel" as one of the objectives of urban plans (SCoT and PLU). Several recent PDUs have been drawn up to link transport and urban planning better, like the 2011 Nantes PDU whose first topic is to build a town in which trips are short, or that of Montpellier in 2012 which clearly shows its consistency with the SCoT.

The link that the PDU has with urban planning and the town also comes into effect more locally in issues of space design. The SRU law makes improved safety for all trips one of the eight goals of the PDU. By giving the PDU a more important role in road sharing, to the advantage of active modes, and in the management of public parking, this law promotes an improved living environment.

The PDU, successfully adopted by cities, is now increasingly popular in medium-sized towns, to the extent that, of the 150 planning steps for urban mobility in France, three out of five were initiated on a voluntary basis, in towns with fewer than 100,000 inhabitants. In addition, since 2007 Europe has been promoting sustainable urban mobility plans in its Green Paper on urban mobility, the PDU being one of the models alongside the English "local transport plan" (LTP).

However, it is difficult to attribute recent travel developments to the PDU alone: the economic environment and rising fuel prices play an important role in the choice of mobility. And while changes are broadly moving in the direction indicated by policies, several results need to be consolidated. For example, all regions do not follow the same trends. While car use is declining in large cities, it continues to increase in the outskirts as a result of continued urban sprawl in the second and even third ring around urban centres, as well as in medium-sized towns. Links between transport and urban planning remain to be consolidated, and PDUs must look further than the centre of urban areas to offer alternative mobility solutions adapted to all types of regions.

The growth in living areas and the increasing distance between home and workplace have not been systematically followed by an extension of administrative boundaries.

Mobility planning in these areas can be organised within the framework of thinking on the SCoTs (area coherency schemes) whose boundaries correspond more closely to living areas. Municipalities outside the PTU may make more fine-tuned use of SCoT principles in municipal transport plans, or as part of the PLU (local urban development plan) that may contain many actions related to mobility.

In addition, transport thinking at departmental and regional level also provides an opportunity to grasp mobility issues in sparsely populated areas in the outskirts of urban areas. As such, the "regional intermodality scheme" that could be introduced by decentralisation Act III should deal carefully with transport planning in areas not covered by the PDU. 
There is a real need for discussion and cooperation between transport authorities to jointly develop mobility solutions that transcend administrative boundaries.

\section{Regional and departmental transport}

The division of powers between the different echelons of local government (regions, departments, municipalities, and groups) - is specified under the LOTI law, which sets out the organisation of local public transport in France.

\section{Regions}

As the authority responsible for the organisation of regional passenger transport, the region ensures scheduled non-urban regional-level services, including:

- Passenger rail services on the TER regional express network, which run on the national rail network (except national-level and international services);

- Non-urban regional-level road passenger services, such as rail replacement coach services; and

- The drafting of regional transport plans - scheduled non-urban regional-level services.

The network carries 700,000 passengers a day, on 5,700 trains. It has its own staff and equipment. Most regions also have subcontracted TER coach services which include road-only services.

Table 1. TER regional express network

\begin{tabular}{|c|c|c|c|c|c|c|}
\hline Region & ion & $\begin{array}{l}2009 \text { TER } \\
\text { budget }\end{array}$ & $\begin{array}{l}\text { Share of } \\
\text { regional budget }\end{array}$ & $\begin{array}{l}\text { Budget per } \\
\text { capita }\end{array}$ & $\begin{array}{l}\text { Train-km } \\
\text { per year }\end{array}$ & $\begin{array}{l}\text { Journeys } \\
\text { Per year }\end{array}$ \\
\hline TER Alsace & $\begin{array}{r}1,843,0 \\
53\end{array}$ & $€ 172.19 \mathrm{~m}$ & $20.55 \%$ & $€ 93.43$ & & \\
\hline TER Aquitaine & $\begin{array}{r}3,206,1 \\
37\end{array}$ & $€ 167.2 \mathrm{~m}$ & $12.31 \%$ & $€ 90.72$ & & $14,782,500$ \\
\hline TER Auvergne & $\begin{array}{r}1,343,9 \\
64\end{array}$ & $€ 97 \mathrm{~m}$ & $14.52 \%$ & $€ 52.63$ & & \\
\hline TER Burgundy & $\begin{array}{r}1,642,4 \\
40\end{array}$ & $€ 181.7 \mathrm{~m}$ & $22.64 \%$ & $€ 98.59$ & $9,800,000$ & $15,953,055$ \\
\hline TER Brittany & $\begin{array}{r}3,175,0 \\
64\end{array}$ & $€ 95.1 \mathrm{~m}$ & $7.89 \%$ & $€ 51.60$ & & $9,500,000$ \\
\hline TER Centre & $\begin{array}{r}2,538,5 \\
90\end{array}$ & $€ 123 \mathrm{~m}$ & $9.87 \%$ & $€ 66.74$ & & $18,888,750$ \\
\hline $\begin{array}{l}\quad \text { TER } \\
\text { Champagne- } \\
\text { Ardenne }\end{array}$ & $\begin{array}{r}1,337,9 \\
53\end{array}$ & $€ 94.4 \mathrm{~m}$ & $14.19 \%$ & $€ 51.22$ & & $3,650,000$ \\
\hline $\begin{array}{l}\text { TER Franche- } \\
\text { Comté }\end{array}$ & $\begin{array}{r}1,168,2 \\
08\end{array}$ & $€ 71.26 \mathrm{~m}$ & $13.89 \%$ & $€ 38.66$ & & $7,300,000$ \\
\hline $\begin{array}{l}\quad \text { TER } \\
\text { Languedoc- } \\
\text { Roussillon }\end{array}$ & $\begin{array}{r}2,610,8 \\
90\end{array}$ & $€ 117 \mathrm{~m}$ & $9.47 \%$ & $€ 63.48$ & $7,100,000$ & $7,300,000$ \\
\hline TER Limousin & 741,785 & $€ 57.41 \mathrm{~m}$ & $12.31 \%$ & $€ 31.15$ & & $2,190,000$ \\
\hline TER Lorraine & $\begin{array}{r}2,350,1 \\
12\end{array}$ & $€ 169 m$ & $16.16 \%$ & $€ 91.70$ & $10,600,000$ & $23,360,000$ \\
\hline $\begin{array}{c}\text { TER Lower } \\
\text { Normandy }\end{array}$ & $\begin{array}{r}1,470,8 \\
80\end{array}$ & $€ 85.5 \mathrm{~m}$ & $11.23 \%$ & $€ 46.55$ & $3,700,000$ & $4,100,000$ \\
\hline $\begin{array}{r}\text { TER } \quad \text { Midi- } \\
\text { Pyrénées }\end{array}$ & $\begin{array}{r}2,862,7 \\
07\end{array}$ & $€ 156.57 \mathrm{~m}$ & $12.71 \%$ & $€ 84.95$ & $9,500,000$ & $11,000,000$ \\
\hline $\begin{array}{l}\text { TER Nord-Pas- } \\
\text { de-Calais }\end{array}$ & $\begin{array}{r}4,033,1 \\
97\end{array}$ & $€ 294.36 \mathrm{~m}$ & $13.4 \%$ & $€ 159.71$ & & $40,880,000$ \\
\hline $\begin{array}{l}\text { TER Pays de la } \\
\text { Loire }\end{array}$ & $\begin{array}{r}3,539,0 \\
48\end{array}$ & $€ 163.1 \mathrm{~m}$ & $12.51 \%$ & $€ 88.94$ & $8,942,500$ & \\
\hline TER Picardy & $\begin{array}{r}1,911,1 \\
57\end{array}$ & $€ 220.3 \mathrm{~m}$ & $20.43 \%$ & $€ 119.53$ & & $20,659,000$ \\
\hline
\end{tabular}




\begin{tabular}{|c|c|c|c|c|c|c|}
\hline $\begin{array}{c}\text { TER } \\
\text { Charentes }\end{array}$ & $\begin{array}{r}1,760,5 \\
75\end{array}$ & $€ 57 \mathrm{~m}$ & $8.32 \%$ & $€ 30.93$ & & $3,577,000$ \\
\hline $\begin{array}{l}\text { TER Provence- } \\
\text { Alps-Côte d'Azur }\end{array}$ & $\begin{array}{r}4,889,0 \\
53\end{array}$ & $€ 273.7 \mathrm{~m}$ & $13.87 \%$ & $€ 148.50$ & $10,500,000$ & $23,400,000$ \\
\hline $\begin{array}{l}\text { TER Rhone- } \\
\text { Alps }\end{array}$ & $\begin{array}{r}6,174,0 \\
40\end{array}$ & $€ 465 \mathrm{~m}$ & $19 \%$ & $€ 252.30$ & & $49,275,000$ \\
\hline
\end{tabular}

\section{Departments}

Non-urban and inter-urban transport is managed by departments. Inter-urban departmental transport includes regular and on-demand road services (see Chapter 4) that may be delegated by the department to secondary transport authorities, i.e. municipalities or groups.

The departments' public transport responsibilities include:

- Drafting the departmental plan for the management of public transport (scheduled and demand-responsive services);

- Organising non-urban road passenger transport;

- Operating rail or non-urban guided transport infrastructure;

- At the request of the municipalities, ensuring all or part of the organisation and implementation of transport services; and

- Pursuing policies to connect rural areas to the public transport network.

In 2009, total departmental public road services were estimated at 680 to 800 million kilometres:

- $59 \%$ of this figure is accounted for by school services, i.e. an average 19 kilometres per capita outside the PTU;

- $\quad 39 \%$ represents scheduled services, i.e. an average of $13 \mathrm{~km}$ per capita outside the PTU;

- Transport on demand (ToD) represents $2 \%$ of total network kilometres.

In 2009, the total number of journeys, excluding school services, was estimated at between 270 and 330 million:

- School attendance on scheduled services accounted for $79 \%$ of journeys;

- $20 \%$ of journeys were made by non-school passengers on scheduled services;

- ToD customers accounted for $1 \%$ of journeys.

General Councils want to densify departmental networks and turn them into key instruments of public mobility in inter-urban areas. They have two means of achieving this goal: increasing the level of service and increasing coverage of the territory.

Under today's tough economic conditions car travel is becoming more expensive. This, combined with growing public awareness of the environmental challenges posed by transport, will prompt departmental public transport to play an increasing role in people's everyday mobility in sparsely populated areas, if sufficient resources are found to establish a credible, financially viable offer. 


\section{School transport}

School transport is organised by the department, but also comes under the responsibility of the French transport authority (autorité organisatrice des transports - AOT) if it is also covered by a PTU, unless this responsibility has been delegated to the department.

The division of responsibilities for school transport between the different regional authorities is as follows.

The General Councils are responsible for organising school transport outside PTUs. Traditionally, they have focused services on primary and secondary schoolchildren, but have extended their mission to the point of becoming a key player in everyday mobility for peri-urban and rural areas.

Since 2006, there has been an increase in both the number of journeys made by schoolchildren, and the number made by other users, especially commuters, on scheduled services.

This trend has also seen an extension of the network, despite the contraction of the service area, owing to the extension of urban perimeters, and greater cooperation with the other transport authorities with the aim of offering a service that is unrestricted by jurisdictional boundaries. In this respect, attractive pricing policies have an important role to play.

The estimated number of school journeys on scheduled services and on special school lines in 20069 is estimated at between 615 and 755 million.

Departmental AOTs have long been seen as specialised in transport services for schoolchildren and students but now, calling on the expertise linked to this decentralisation, they are moving into a new role by extending their services. A recent survey identified the trend towards departmental lines open to all users, structured in a hierarchical network, like the urban model. They are now working towards converging scheduled services with school services in order to encourage a network-based approach.

\section{Demand-responsive transport: a high level of flexibility for transport services}

Improving mobility is a major issue in sparsely populated areas. The low population density in these localities often means that longer journeys are required to access services, carry out everyday activities or maintain social links.

Demand-responsive transport (DRT) or Transport-on-Demand (ToD) is a public transport service that is attracting a great deal of interest among local authorities as an alternative transport solution to the private car and regular public transport services in cases where the latter are no longer appropriate. Transport-on-demand runs only at the express request of the people that need to use it and is distinguished from regular transport services that follow set routes and run according to timetables that are defined on an annual basis. Given the way in which it functions, transport-on-demand is a transport service that is halfway between regular public transport and taxi services.

The right to transport is enshrined in French legislation, in particular the LOTI law and its article 2 which institutes a right to transport allowing users to travel in reasonable conditions in terms of access, quality and price, in particular by using a mode of public transport. 
The application of this law in sparsely populated areas is difficult, as conventional public transport services are not always suitable: high-volume transit, the fundamental principle behind these services, is not applicable here, as the population is too widely dispersed.

Furthermore, it is becoming more and more difficult for conventional public transport services to meet increasingly complex and individualised mobility needs. Nevertheless, there is a real demand for mobility in these areas (whether for leisure, shopping or work purposes), together with growing concerns regarding sustainable development.

Indeed, faced with the challenges of sustainable development, noticeable changes are being made to transport policies. The objective is no longer to adapt supply to fluctuating demand, but to try to concentrate and direct this demand towards economical, efficient and environmentally friendly forms of mobility.

From this point of view, demand-responsive transport can be considered as a way of optimising transport in order to meet the needs of rural or semi-rural areas and ensure that the transport services on offer are suited to the areas and populations in question.

\section{Different forms of demand-responsive transport}

Demand-responsive transport (DRT) can provide a solution that is particularly suited to sparsely populated areas, thanks to its flexibility, its ability to adapt to local contexts, to many users' requirements, and the fact that costs can, to some extent, be controlled. Local authorities have several options to choose from:

- A "virtual" line. A virtual line is a service that is similar to normal scheduled services since it stops at fixed stopping points, follows regular routes and runs according to timetables set in advance. The basic difference compared with normal scheduled services is that it only runs if requested by one or more users.

- A "Door-to-Door" service. A Door-to-Door service, although less common, is a service transporting users from their homes to specified destinations. It is reserved for the elderly or for people with reduced mobility. There is no set route in this case and the service may be provided by taxis or minibuses belonging to the main network operator.

- Stop-to-stop or "point-to-point" services. Stop-to-stop or point-to-point refers to a system that serves an area with stops defined in advance. Routes may vary depending on stops and user demand. It may also make use of taxis or minibuses.

In addition to these main categories, there are many intermediate forms that may be a combination of the main variants. For example, transport-on-demand services sometimes run on market days without any need to book but stopping at stops that are specified in advance.

\section{The responsible authority}

The transport authority defines the main characteristics of transport services within its area, including pricing policy. Unlike scheduled services, timetables and routes for demand-responsive transport services may change in order to meet demand more effectively. One of the objectives for transport authorities is to ensure the economic viability of DRT services, even though passenger numbers are often limited. The fixed costs remain the same regardless of whether the service is operational. These costs include the purchase of vehicles, and the fact that these vehicles cannot be used for other purposes, as well as the cost of keeping drivers and vehicles on standby. However, the transport authority can control costs associated with the operation of the service, in particular by encouraging passengers to share the same vehicle or even by recommending the use of DRT services on certain days or at certain times. 
In the context of non-urban road-based passenger transport, demand-responsive transport services are public services, the organisation of which is usually the responsibility of departmental councils. However, if municipalities or groups of municipalities so wish, the department may entrust them with all or part of the organisation and implementation of these services. In this case, the terms of such a partnership are laid down in an agreement between the two structures, and the organising body is then known as a second-tier transport authority (autorité organisatrice de second rang ).

\section{Relevance of demand-responsive transport}

One of the major problems encountered when setting up a transport-on-demand scheme is the difficulty in correctly gauging demand for the service. To ensure success, emphasis should be placed on preliminary research and studies, which are crucial for correctly assessing potential demand and the nature of transport services required.

Demand-responsive transport services must be developed in consultation with users - much more so than for conventional services. Indeed, the creation and long-term success of a DRT service is entirely dependent on the involvement of everyone in the local community.

Transport-on-Demand is usually developed to serve periurban areas, where providing an adequate scheduled service cannot be justified as demand is not high enough. ToD is a cheaper and more suitable way of connecting certain periurban districts to the town centre. This arrangement is of particular interest for medium-sized towns, which typically have a densely populated centre and a population scattered more widely across the surrounding area, compared with the built-up centre.

Whole sections of the population -older people, young people, stay-at-home parents in single-car households, and seasonal workers - are effectively handicapped in mobility terms by inadequate public transport provision and overdependence on people with cars.

Developing transport-on-demand may also be a solution for dealing with limited financial resources and a need to rationalise services, by finding alternative ways to supplement regular public transport services.

From transport-on-demand on a large scale, covering an entire agglomeration, to end-of-line transport-on-demand continuing from the end of the transport network, the area covered may vary depending on the objectives targeted by the authorities.

\section{Organisation}

Transport-on-demand schemes come in various forms, all of which afford varying levels of flexibility. They may be run by different types of operator, mainly transport companies and taxi firms. In most cases, the local authority entrusts the running of transport-on-demand schemes to the major public transport network operator, which either runs the services itself or subcontracts them to a thirdparty operator. There are some cases where the third-party operator contracts directly from the organising authority. Such rationalisation may also involve the use of taxis, which implies the availability of a fleet of vehicles that usually costs less than that of the urban transport operator. There are also some agglomerations that decide to manage a transport-on-demand service themselves, using their own personnel and vehicles.

Timetables and routes are usually decided by the relevant passenger transport authority after discussions with residents of the towns and villages concerned.

In terms of organisation, pricing and publicity, it is essential for the transport-on-demand scheme to be linked up to any scheduled services that exist with a view to developing an integrated public transport system. 
It is also essential for the local authority to monitor the running of the service with a view to adjusting the offer as closely as possible to users' needs. Transport-on-demand schemes are not intended as a replacement for scheduled urban services. They have to be adapted to the social and economic context in a given area. The appropriate service (type of line, vehicles and operators) to be developed will depend on demand for mobility in the area.

Promoting the service is also essential to inform the public of transport-on-demand services, thereby attracting sufficient numbers of users to be able to provide an optimal service. Encouraging new customers to use the service should, however, be done within certain limits, to maintain the financial viability of the service.

In spite of this diversity of service and the variety of management contracts involved, the cost for the user is usually the same as that paid for regular urban transport services.

\section{BOX. CHOOSING A FARE SYSTEM}

- Flat-rate fares: this is the system usually adopted. The fare is the same regardless of the distance travelled.

- Distance-based fares: this system seems more appropriate from an economic point of view, as it reflects the operator's actual cost structure, but it can become quite complex, depending on the routes involved In order to rationalise costs, one vehicle may pick up several passengers at different locations, and each would then pay a different fare based on the real cost of their journey.

- Zone-based fares: this system allows a distinction to be made between a number of sectors in a large area.

- Degressive fares: this system is generally used to encourage passengers to group together and to avoid competition with taxi firms.

- Integrated fares: using the same fare system for DRT services and interurban (or urban) transport lines, facilitating connections with these services.

\section{Other solutions}

Demand-responsive transport services provide a mobility solution for sparsely populated areas, offering users connections to rail services, departmental coach services and urban bus routes.

However, they should not be considered a cure for all transport-related ills, for several reasons:

- In practice, these services, though used by all, are used mainly by older people;

- The cost is still considered too high by many transport authorities, which have limited resources; and

- Demand-responsive transport is not yet flexible enough to trigger a modal shift among motorists in what are heavily car-dependent areas. While the positive image of demandresponsive transport among users encourages operators to expand the services they offer (e.g. new routes, extended timetables and coverage), the key to providing comprehensive mobility services in low-density areas (where car use is high) lies in the diversification of services by 
means of other innovative procedures (e.g. bicycle or moped rental, mobility switchboards, carpooling, car-sharing).

\section{Carpooling}

Carpooling helps relieve congestion and pollution by reducing the number of vehicles on the road. A national survey of all travel in France in 2008 - Enquête Nationale Transports et Déplacements found an average of just 1.4 people per vehicle, a figure that falls to 1.1 for commuters.

Carpooling offers real growth potential, as a form of mobility that can be harnessed at no cost to the public purse, and the last decade has seen a proliferation of initiatives, both public and private.

Alongside public transport, carpooling represents another form of transport that reconciles the need for mobility with environmental and economic imperatives, and is widely seen as a good solution for sparsely populated areas with poor access to affordable public transport, and for times when public transport is not available. For these reasons, the French government has taken steps to encourage the practice.

Carpooling is not new. It was started by people without access to a vehicle, and those looking to save money. But it seems to have found renewed popularity, spurred by today's new information and communication technologies.

Valuable support can be offered by the local authorities responsible for urban planning, road planning, and the organisation of local public transport. Other players, including the government, can make a decisive contribution; the adoption of this mode of transport will require the various parties involved to make regulatory, organisational and technical changes.

The development of carpooling would benefit from several actions:

- actions helping carpooling services to reach a critical size, in order to increase the chances of finding suitable itineraries:

- promoting interoperability among carpooling services, to share data between operators;

- counteracting the proliferation of services by developing interoperability between operators and using compatible databases;

- promoting carpooling and communicating about local opportunities to encourage people to adopt the practice ;

- the development of dedicated infrastructure: carpooling park networks, connected with public transport as often as possible, dedicated lanes (HOV lanes).

\section{Active modes}

For a long time, walking occupied a marginal place in the PDUs, whereas it is the second transport mode after the car.It is now making a very noticeable appearance in mobility policies, in conjunction with a more balanced sharing of public space, the problem of road accessibility for people with reduced mobility and the promotion of so-called active modes with a view to improving public health.

Cycling has found its way into more PDUs since the 1996 air quality law. Although its share of travel rarely exceeds $2 \%$, it is identified as high potential, as many European towns have implemented proactive and successful policies in this field, especially in Northern Europe.

Measures to encourage these modes are designed to support a more general urban planning policy to promote local travel, a prerequisite for walking and cycling as standalone modes of transport or as feeders to public transport networks. 
Walking and cycling are good modes of transport for short journeys, e.g. between municipalities or from a hamlet to the neighbouring village. They are also suitable for accessing stations.

One of the main ways to encourage walking and cycling is to offer safer, more attractive walkways and cycle paths. A particularly illustrative example of a shifting trend concerns the journey to school taken by primary schoolchildren.

Primary schoolchildren, aged between five and nine, make almost all trips to school either on foot or by car, and over the last thirty years, these modes have shown inverse trends, as walking has declined. Car use has grown strongly - more than doubling over this period.

The last survey, however, identified the end of this marked trend, reflecting a decline in car use also seen elsewhere. This may be partly due to policies implemented in the last ten years, such as Pédibus. Pédibus is a walking bus is a form of student transport for schoolchildren who, chaperoned by two adults walk to school, in much the same way a school bus would drive them to school. Like a traditional bus, walking buses have a fixed route with designated "bus stops" and "pick up times" in which they pick up children.

\section{Mobility Management}

Mobility management consists of "promoting sustainable transport and managing the demand for car transport by changing the attitudes and behaviours of people and businesses. It is based on 'soft' measures, such as information and communication, service organisation, and the coordination of the various parties involved."

Based on this definition, a certain number of characteristics can be established. Mobility management:

- aims to influence the demand for transport instead of increasing the supply ad infinitum;

- consists essentially of communication, awareness-raising, education, and the adaptation and organisation of transport services and pricing, with dedicated staff and facilities;

- occasionally requires targeted investments and measures to stimulate the modal shift to alternative forms of transport to solo car journeys (e.g. creation of cycle parks, reduction of number of parking spaces, creation or displacement of public transport stops);

- generally concerns passenger transport, but may also concern freight, especially when rationalising the logistics of a given business location.

It is not possible to change mobility practices overnight; lasting change will only happen after a process of successive, intermediary steps. 
Figure 1.1. The "stairway" to new mobility practice

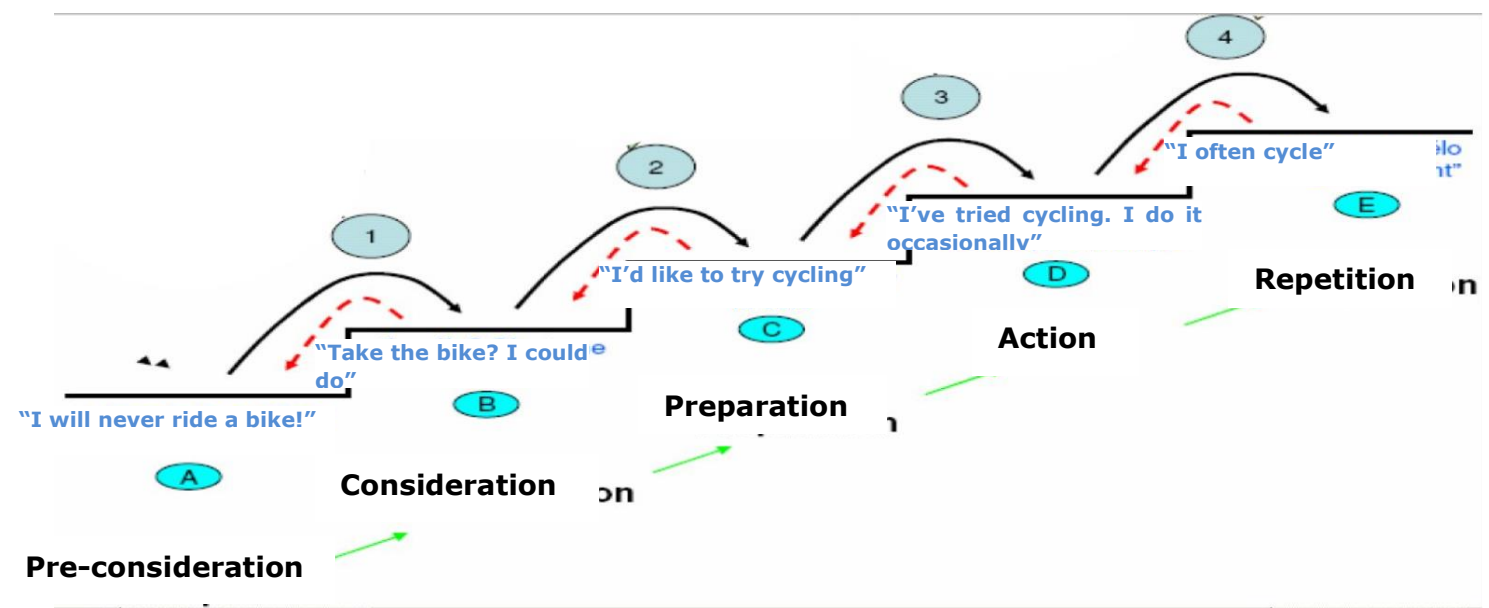

Source: RR\&A Roland Ribi \& Associés pour la Communauté Urbaine de Strasbourg

Mobility management can make use of various tools:

1. Tools for organisational intervention

- Mobility advice for users and businesses

Mobility advice covers the full range of mobility options. It includes the promotion of travel plans to the managers of business locations. It offers guidance for mobility management. It helps generate solutions by rallying the different parties.

- Teleworking to relax constrained mobility

Teleworking and remote working tools such as videoconferencing, conference calls, etc. provide an opportunity to reduce passenger mobility. They also offer alternatives to relax the mobility constraints experienced by workers (long commutes, etc.).

The links between mobility policies and teleworking have been highlighted by exceptional events such as extreme weather, strikes, and sporting events that affect the normal operation of public transport services.

The gradual emergence of a network of "third places" and telecentres, moreover, may reduce the distance between people's home and their place of work.

2. Tools for communication, education, and awareness-raising

Communication lies at the heart of mobility management. This set of tools can offer quick, tangible results for a low investment.

- Targeted awareness-raising campaigns and communication

The aim is to encourage the public to use existing alternatives to the private car, by means of effective awareness-raising and information campaigns.

- Personalised marketing for tailor-made travel solutions 
Personalised marketing is aimed at individual, targeted people or populations. It is usually very effective, but requires strong political support and dedicated resources.

This kind of campaign involves the distribution of flyers and/or free public transport tickets either door-to-door or on strategic sites such as universities, or telephone campaigns targeting certain people.

3. Tools for scheduling: mobility plans for places of business

These tools are variously known in France as plans de déplacements d'établissements, d'entreprises (PDE), d'administration (PDA) and d'établissement scolaire (PDES), and they can be used by any public or private employer to promote the use of sustainable travel solutions among their employees. They are implemented as projects at the level of the establishment, of one or more sites, or a business park.

Inter-establishment and inter-enterprise travel plans (plans de déplacements interétablissements/inter-entreprises - PDIE) have some advantages over single-site plans, since they offer the critical mass necessary to set up certain sustainable mobility services, such as carpooling and a pool of service vehicles.

The content of the plan varies according to the type of business or administration and its environment. The PDE may involve any of the following (non-exhaustive list):

- employee awareness-raising: e.g. communication about the transport available, challenges and contests, appointment or recruitment of a travel officer;

- arrangement with the appropriate authorities for the creation or displacement of public transport stops close to the site, and for the requisite works to be carried out;

- refunding a greater share of employees' travel costs than required by law;

- creating pedestrian- or cycle-friendly facilities (cycle parks, showers, etc.);

- implementation of measures to limit the negative effects of logistics, such as pollution and congestion, e.g. rescheduling deliveries and redesigning access to the site;

- promotion of technological solutions to reduce business travel, e.g. teleworking and videoconferencing.

PDESs are mobility plans for educational establishments and address issues specific to this sector, teaching young people and their families to adopt active modes and public transport instead of the car.

Securing the lasting success of these mobility plans will require support for the process from management and HR, and regular assessments of the action taken.

Mobility management may make use of information and communication technologies to help underprivileged sections of the population access transport networks.

Applications and services designed to assist travellers, such as information terminals and interactive maps, which offer reliable and accessible travel information and help users understand the operation of the public transport network, can help to promote social integration. 
Lower-income sectors of the population are now adopting smartphones, moreover, as this technology sweeps the market. Mobility management should help these users optimise their mobility by means of these devices, with free journey planning apps, electronic ticketing, etc.

Mobility management first took off in major conurbations with sufficient transport density and infrastructure. It has proved effective in peri-urban and rural areas, however, where some underprivileged households are being driven into poverty by rising fuel prices. This is also a risk for deprived parts of the suburbs, where efficient transport links are often scarce.

These areas happen to be particularly relevant to the expansion of certain mobility services regional trains, carpooling, telecentres. Mobility management needs to take these factors into account to define the right solutions and create a multi-modal network.

\section{Intermodality}

In rural areas, promoting public transport means promoting intermodality, which is defined as the use of several complementary mechanised modes of transport. It does not include walking.

By definition, public transport only serves only points, so coverage of an area requires the additional use of personal travel: driving, cycling or walking. Walking can be adequate in built-up areas, but not in the interurban environment, which requires intermodality. Intermodality is therefore far more widespread in periurban areas, especially for trips to or from the city. In Lyon, for example, only $2 \%$ of trips within the urban area are intermodal, but this figure rises to $21 \%$ for people living in the suburbs travelling to the central business district.

Intermodality can mean a wide range of different combinations, however. Intermodality between several public transport networks requires the creation of effective interchanges and timetable coordination. Intermodality between public transport and cars requires the provision of convenient parking, but this is difficult to achieve, given the many different demands for property around interchanges, and may even have negative consequences, such as encouraging urban sprawl and a modal shift away from departmental coach lines. Much can be done to encourage intermodality with cycling, starting with special routes to interchanges, secure cycle parks, and allowing cyclists to travel with their bicycles.

In any event, intermodal travel is more complicated than a simple ride on the bus or train. Users have to make a decision in three parts: knowing (about available transport options and their interchanges), understanding (how each mode of transport works and connects to others), choosing (according to the global performance of the trip in the light of the user's preferences). Multimodal information services are therefore vital to encourage people to practice intermodality.

One of the functions of demand-responsive transport is to improve intermodality. DRT has an important role to play in modal shift, specifically in the context of its integration with conventional public transport services. In order to ensure that a substantial volume of journeys are made via DRT across a wide area, as a complement to the fixed networks, priority must be given to serving key transport hubs. 
For successful intermodal integration, it is advisable not only to apply the same fare scheme (and even the same ticketing arrangements) as the conventional network, but also to make DRT timetable and fare information available from the same sources (e.g. all in a single network guide) and use shared bus stops. In addition, to ensure the success of intermodality with regard to passenger information, urban transport authorities are setting up mobility switchboards, which typically provide information on the public transport services on offer, as well as other transport modes. These switchboards can also play an essential role for demand-responsive transport services, by enabling users to plan intermodal journeys (e.g. DRT service and conventional service).

\section{Conclusion}

Mainly devoted to the densest areas of urban transport zones, PDU actions are often hard to implement in the peripheral areas of cities: the density is less favourable to public transport, the areas are less built up and are divided into sectors, encouraging the use of private cars and long-distance trips, etc. However, there are solutions, in terms of urban planning, public transport, and green mobility. Each mode has its own area in which it provides a relevant solution.

For public transport, a network hierarchy makes it possible to use rail services, and identify key urban lines running in dedicated spaces, to which transport lines can be connected, either as a scheduled service or on demand.

Intermodality has also a role to play in expanding the public transport user base. The shared use of cars is also relevant: facilitating carpooling by creating dedicated car parks and effective internet platforms for linking motorists, offering carpooling services and making parking easier for these new modes than solo car users.

Green mobility already represents a high proportion of travel in town centres in rural areas, because local services are often available within walking or cycling distance. It can be further aided by working on the development of traffic-calming areas and cycle parking, but also on awareness and education, especially as far as cycling is concerned.

France is beginning to see a separation of the ideas of car use and car ownership. People's attitudes to the environment and global warming are (slowly) changing, with positive results. Public awareness of environmental problems may not have led to many changes in behaviour, but it is encouraging people to take "virtuous" action, generally in response to new restrictions.

Reduced car use may eventually encourage carpooling and car sharing or, in other words, the "collective" car, as society transitions between exclusive car use and a more rational, "detached" approach to this mode of transport. 



\section{Annex Taxis in France}

Taxis are specially equipped motor vehicles with seating for no more than eight people, in addition to the driver, whose owner or operator is licensed to wait at taxi ranks on the public highway for customers, on whose request the operator will provide private transport of people and their luggage in return for payment, as provided for by Article L.3121 of the French Code des Transports.

When waiting for customers, taxis may only use taxi ranks in their home district, i.e. the municipality (commune) in which they are registered, or in a municipality covered by a shared provision of taxi services that also includes their home district. They may also use taxi ranks in municipalities in which they have received a pre-booking, proof of which must be presented at the request of an authorised official, as provided for by Article L.3121-11 of the Code des Transports. Taxis can be hailed in the street.

Taxis are an essential adjunct to public transport. The mass transport solutions offered by scheduled public passenger services cannot provide round-the-clock coverage of the entire territory; because of their flexibility and adaptability to user demand, taxis are an effective means of filling the gaps left by the regular public transport system.

\section{Taxi services in France}

French taxi drivers are highly regulated. France has a total of 51232 licensed taxis, and Paris has 16 623. In Paris, taxis are regulated by the Police Commissioner (Préfet de Police) of the City of Paris.

French taxis may be any colour. Their main distinctive characteristic is a roof light marked "TAXI". A green light indicates that the taxi is available and a red light that it has been hired. Taxis must also have an approved time-distance meter, or taximeter, a plaque welded to the vehicle and, since 31 December 2011, a printer for the automatic issue of a receipt.

There are different legal statuses for taxi drivers:

- Sole trader (around 80\%);

- Self-employed (using a leased vehicle) (around 11\%);

- Self-employed (member of a co-operative) (around 6\%); and

- Employees (around 3\%).

Taxi drivers have to pass an exam to receive a certificate of fitness to drive a taxi from the police, and they must have a licence to wait for custom at taxi ranks (see Article L.3121-1 of the Code des Transports), acquired from a sole trader or company that is winding up its business.

In order to be able to ply for hire, taxi drivers must be in possession of an autorisation de stationnement (AdS), also known as a licence, which is initially issued free of charge by the local mayor or prefect. Before obtaining the licence, applicants must add their name to a waiting list at the town hall or the prefecture, and the Commission for taxis and private hire vehicles delivers its opinion. 
After they have been issued, licences can be sold freely between sole traders after fifteen years of business, or five if the licence has been sold previously. The estimated cost of a Parisian licence was estimated at around $€ 240000$ in 2013.

Under certain conditions, a taxi driver can pay to present a successor to the administrative authority that issues the licences (see Article L.3121-2 of the Code de Transports).

\section{Legal framework}

Taxi drivers provide transport for hire or reward, which constitutes public transport as defined by Article 5 of the LOTI law (loi d'orientation des transports intérieurs - French framework law on domestic transport) but for commercial gain and not as a public service. They are governed by specific legislation laid down by the interior ministry.

Taxis have the option of operating in both capacities, however, in that there is no law which precludes them from responding to calls for tender issued by a transport authority for demandresponsive transport (DRT).

Should they choose to do so, they must adhere to the rules applicable to public transport activities and the principles of the LOTI:

- Taxi drivers who want to offer DRT must have signed the register of public road transport operators;

- Demand-responsive transport authorities can sign contracts with taxi drivers after a competitive process.

Taxi drivers come under the authority of the local mayor, who sets, if necessary, the number of taxis that may operate in the municipality, issues licences and makes rules subjecting the licences to conditions concerning the time drivers may start work or the pattern of shifts throughout the day, and specifies pick-up zones.

\section{Fares}

Fares are calculated per journey, regardless of the number of passengers. They include:

- A maximum pick-up cost;

- A maximum price per kilometre.

The minister of the economy determines the annual fare increase for a daytime journey of seven kilometres, including pick-up cost and six minutes' waiting time or low speed driving, taking account of price fluctuations in fuel, repairs and maintenance, insurance and vehicle costs.

As part of this process, fares are set every year by a prefectural order, which does not stipulate a legal rate, but a cap. Flat rates are not permitted; fares must be calculated according to distance and, at low speeds, time.

The current caps are:

- $€ 3.79$ (compared to $€ 3.65$ in 2013) for the pick-up cost;

- $€ 1.04$ (compared to $€ 1$ in 2013) per kilometre; and

- $€ 34.91$ (compared to $€ 33.60$ in 2013) for an hour's waiting time or low speed driving. 
Fares are calculated differently between Paris - where rates are higher during rush hour, at night, on Sundays and on bank holidays - the Paris suburbs, and the rest of France.

Parisian taxi drivers may only apply prefectural rates, which take account of both time and distance. The total fare is calculated automatically by the meter inside the vehicle.

Fares are calculated per journey, regardless of the number of passengers.

\section{Private hire vehicles and chauffeur-driven passenger vehicles}

Private hire vehicles are motor vehicles with seating for no more than eight people in addition to the driver, that are made available to people on their request and in return for payment, with a driver, for the private transportation of themselves and their luggage, as provided for by Article L.3122-1 of the Code des Transports.

Chauffeur-driven passenger vehicles must have at least four seats and no more than nine, including that of the chauffeur, according to the provisions of Article D.231-1 of the French Code du Tourisme. These vehicles, as distinct from private hire vehicles, must meet specific conditions of comfort and interior furnishings and fittings.

Unlike taxis, private hire vehicles and chauffeur-driven passenger vehicles may not be hailed or wait for custom in taxi ranks on the public highway unless they have been booked in advance. Taxis also have their own specific furnishings and fittings, and only taxi fares are regulated. For private hire vehicles and chauffeur-driven passenger vehicles, the price is freely agreed between the operator and the customer. 
